\section{Determinantes e padrões de utilização da bicicleta e acidentes de trânsito sofridos por ciclistas trabalhadores da cidade de Pelotas, Rio Grande do Sul, Brasil}

\author{
Determinants and patterns of bicycle use \\ and traffic accidents among bicycling workers \\ in Pelotas, Rio Grande do Sul, Brazil
}

Giancarlo Bacchieri 1,2

Denise Petrucci Gigante 1,2,3

Maria Cecília Assunção 1,3

\title{
Introdução
}

1 Centro de Pesquisas Epidemiológicas, Universidade Federal de Pelotas, Pelotas, Brasil.

2 Centro Federal de Educação Tecnológica de Pelotas, Pelotas, Brasil.

3 Faculdade de Nutrição, Universidade Federal de Pelotas, Pelotas, Brasil.

\section{Correspondência} G. Bacchieri Centro Federal de Educação Tecnológica de Pelotas. Praça 20 de Setembro 455, Pelotas, RS

96015-360, Brasil.

gibac@hotmail.com

\begin{abstract}
A population-based cross-sectional study was conducted in Pelotas, southern Brazil, focusing on the determinants and patterns of bicycle use as a mode of commuting by workers. Accidents during commuting and use of safety equipment were also studied. The sample included 1,705 workers ( $\geq 15$ years of age) living in the urban area of Pelotas and using various modes of transportation during commuting. Crude and adjusted analyses were performed using Poisson regression, taking the design effect into account. Prevalence of bicycle use was 17.2\% (95\%CI: 15.4\%-19.0\%). Male workers and those with low schooling and low income presented higher prevalence. Less than 1.0\% of the bicycles featured the safety equipment required by the Brazilian Traffic Code, and 15.0\% did not even have brakes. Nearly 6.0\% of workers who commuted by bicycle had suffered accidents resulting in injuries during the previous 12 months. The authors conclude that bicycling workers are a priority for interventions aimed at reducing traffic accidents.
\end{abstract}

Traffic Accidents; Workers; Bicycling
Desde o século XIX, a bicicleta tem sido um modo de transporte eficiente e popular entre vários povos do mundo. Por seu baixo custo de aquisição e manutenção, a bicicleta pode ser considerada como o modo de transporte urbano mais barato, sendo acessível a praticamente todas as camadas sociais. Sua utilização não polui o meio ambiente, preserva os espaços públicos e não provoca os incômodos que caracterizam a utilização dos veículos motorizados em áreas urbanas 1 .

A utilização da bicicleta como modo de transporte urbano no mundo é bastante variável. Países do norte da Europa, como a Dinamarca e a Holanda, apresentam altos níveis de utilização, cerca de 20,0 e 30,0\%, respectivamente 2 . Na China, apesar da redução devido às mudanças políticas e econômicas ocorridas no país no início da década de 90 , a bicicleta ainda é o principal modo de transporte, sendo responsável por $40,0 \%$ dos deslocamentos urbanos ${ }^{3}$. Nos Estados Unidos e Canadá, menos de $1,0 \%$ desses deslocamentos são realizados de bicicleta 2 , mas tem-se observado um aumento na sua utilização nas décadas de 80 e 904 .

Com aproximadamente 48 milhões de bicicletas, existem, no Brasil, poucos estudos relacionados à utilização dessas como modo de transporte ou mesmo como atividade de lazer. 
Em 2001, a Empresa Brasileira de Planejamento de Transportes (GEIPOT) 5 realizou um levantamento sobre a importância da utilização da bicicleta como modo de transporte em sessenta municípios brasileiros, intitulado Planejamento Cicloviário: Diagnóstico Nacional. Esses dados revelam que quase dois terços da frota de bicicletas são utilizados como modo de transporte da classe operária.

Os benefícios para a saúde devido à utilização regular da bicicleta, tanto nos deslocamentos utilitários quanto no lazer, são inegáveis. Estudo realizado na Dinamarca mostrou que a utilização da bicicleta como modo de transporte reduz o risco de mortalidade por doenças crônico-degenerativas 6 .

Movimentos para incentivar o uso da bicicleta, principalmente nos deslocamentos para o trabalho, estão surgindo em várias partes do mundo. O Dia Mundial Sem Carro, iniciado na França em 1998 e hoje organizado pela União Européia, é realizado em várias cidades do mundo, incluindo cidades brasileiras (European Mobility Week. http:/ / www.22september.org, acessado em 04/Ago/2004).

O programa americano Healthy People 2010 (Office of Disease Prevention and Health Promotion. http://www.healthpeople.gov, acessado em 05/Abr/2004), apoiado pela Organização Mundial da Saúde (OMS), tem por meta reduzir a inatividade física e conseqüentemente as morbi-mortalidades por doenças crônicodegenerativas. Uma das principais formas de alcançar a meta proposta é incentivar os trabalhadores a utilizarem modos de transporte alternativos (caminhada ou bicicleta) em seus deslocamentos para o trabalho.

Em contraponto ao saudável uso da bicicleta como modo de transporte, atividade esportiva ou de lazer, acidentes de trânsito envolvendo ciclistas são freqüentes em vários países, causando mortes e incapacidades, principalmente em crianças e adultos jovens 7,8,9,10.

No Brasil, estudos relacionados a acidentes de trânsito apontam para a existência de subregistro nos dados, os quais subestimam o número de vítimas. Em Pelotas, Rio Grande do Sul, Brasil, Barros et al. 11, comparando informações de boletins de ocorrência e atendimentos no pronto-socorro durante dois anos, encontraram 33,0\% de sub-registros relativos aos acidentes com lesão corporal envolvendo ciclistas. Em Londrina, Paraná, a cobertura de registro policial para acidentes de bicicleta foi de $8,0 \%$, enquanto que para acidentes de carro, essa proporção foi de $72,0 \% 12$.

As características climáticas e topográficas de Pelotas, bem como as distâncias entre o cen- tro da cidade e os bairros propiciam uma grande utilização desse modo de transporte. Tais características, somadas a uma infra-estrutura cicloviária insuficiente (aproximadamente $10 \mathrm{~km}$ de ciclovias) e à baixa conscientização de motoristas de veículos automotores para a presença de ciclistas em via pública 5 , contribuem para o número considerável de acidentes de trânsito envolvendo ciclistas.

Dados fornecidos pela Secretaria Municipal de Transporte e Trânsito (SMTT) 13 indicam que, no ano de 2003, ocorreram 2.582 acidentes de trânsito em Pelotas, resultando em 706 pessoas com lesões corporais e 44 mortos. Os ciclistas representaram 16,0\% dos feridos (112) e 33,0\% dos mortos (14). Igualmente alta, a taxa de letalidade foi superior a 11,0\%. Esses números são superiores aos encontrados em outros estudos brasileiros que se referem a acidentes com ciclistas. Em Belo Horizonte, Minas Gerais, Gonçalves et al. 10, utilizando dados de ocorrências policiais, mostraram uma taxa de letalidade de 2,0\%, enquanto Scalassara et al. 14, utilizando declarações de óbitos e boletins de ocorrência, apresentou uma taxa de mortalidade proporcional de $18,0 \%$ para os ciclistas da cidade de Maringá, Paraná. Em Londrina, Andrade \& Mello-Jorge 12 encontraram uma taxa de mortalidade proporcional e taxa de letalidade de, respectivamente, $9,0 \%$ e $1,0 \%$. Barros et al. 11, estudando acidentes de trânsito com vítimas, entre os anos de 1997 e 1999, na cidade de Pelotas, demonstraram taxas de mortalidade proporcional e letalidade na ordem de $18,0 \%$ e 5,0\%, respectivamente. Ambos os estudos utilizaram boletins de ocorrência e fichas de atendimento hospitalar.

Este estudo apresenta os determinantes e os padrões de utilização da bicicleta entre os trabalhadores de Pelotas que a usam como modo de transporte, e descreve os acidentes sofridos nos últimos 12 meses por esses trabalhadores, no trajeto do domicílio para o trabalho e vice-versa.

\section{Métodos}

O delineamento do estudo foi transversal de base-populacional, realizado na zona urbana do Município de Pelotas. Situada no extremo sul do Brasil, Pelotas é uma cidade de porte médio com aproximadamente 320 mil habitantes, sendo 93,2\% desses moradores da zona urbana (Instituto Brasileiro de Geografia e Estatística. Censo Demográfico 2000. http: / / www. ibge.gov.br, acessado em 25/Ago/2003).

$\mathrm{O}$ processo de amostragem, realizado em múltiplos estágios, utilizou os setores censitá- 
rios do Censo Demográfico de 2000 do Instituto Brasileiro de Geografia e Estatística (IBGE) como unidade primária amostral. Foram sorteados 144 dos 409 setores de Pelotas, estratificados em relação à renda média do responsável pelo domicílio. Todos os domicílios de cada um dos 144 setores foram classificados quanto ao status de ocupação (residência, comércio ou desabitado). Após a listagem dos domicílios elegíveis (exclusão dos desabitados e puramente comerciais), foram sorteados, sistematicamente, dez em cada setor, sendo que em setores onde se observou maior ou menor número desses em relação ao Censo Demográfico de 2000, foram adicionados ou subtraídos domicílios, proporcionalmente à diferença observada. Indivíduos com 15 anos ou mais de idade, que trabalhavam fora do domicílio e que, portanto, utilizavam modos de transporte, foram incluídos na amostra.

Transcreve-se literalmente a questão utilizada no instrumento de pesquisa deste estudo: a) “O(a) senhor(a) trabalha fora?". Foram considerados trabalhadores todos os indivíduos que referiram estar trabalhando no momento da entrevista, independentemente do tipo de trabalho e da remuneração recebida.

O uso da bicicleta foi definido como modo de transporte referido pelo trabalhador para deslocar-se ao seu local de trabalho.

$O$ acidente de bicicleta foi definido como acidente acontecido nos últimos 12 meses, durante o trajeto domicílio/trabalho/domicílio, em que houve lesão corporal referida pelo entrevistado.

Transcrevem-se literalmente as questões utilizadas:

a) "Qual o meio de transporte o(a) senhor(a) usa para ir e voltar do trabalho?"

b) "Desde [mês] do ano passado, o(a) senhor(a) sofreu algum acidente de bicicleta no caminho de casa para o trabalho ou na volta para casa, em que se machucou?"

Além dos aspectos citados anteriormente, também se estudou os determinantes e os padrões de utilização da bicicleta como modo de transporte no deslocamento para o trabalho e os acidentes sofridos, nos últimos 12 meses, nesse trajeto.

Solicitou-se aos entrevistados que utilizavam bicicleta como modo de transporte permissão para que essa fosse examinada e, assim, anotados os equipamentos de segurança utilizados. Foi questionado diretamente ao entrevistado sobre a utilização de faroletes dianteiros e traseiros, visto que esses são comumente retirados das bicicletas, devido ao receio de furto.

As variáveis independentes foram sexo, idade (anos completos), cor da pele (categorizado em branco e não-branco), escolaridade (anos completos de estudo) e nível econômico (medido através da classificação da Associação Nacional de Empresas de Pesquisa (ANEP) 15, dividido em níveis na análise descritiva e em quintis nas análises bruta e ajustada). As variáveis independentes relacionadas à bicicleta foram: freqüência de uso (número de dias da semana e tempo de utilização por dia), turno de uso (uso da bicicleta à noite), condições meteorológicas (uso em dias de chuva, calor e frio), equipamentos de segurança obrigatórios (campainha; espelho retrovisor; refletores dianteiro, traseiro, laterais e de pedais) e não obrigatórios (freios, lanternas dianteira e traseira). Quanto aos acidentes, as variáveis foram: número de acidentes sofridos no último ano, gravidade do acidente (referido pelo ciclista) e dias de falta ao trabalho em decorrência do acidente.

Para o cálculo do tamanho da amostra foi estimada uma prevalência de $10,0 \%$ para utilização da bicicleta, com erro aceitável de dois pontos percentuais. Para isso seria necessário entrevistar 950 pessoas, já calculados $10,0 \%$ para perdas e recusas. Para investigar a associação entre o desfecho e as variáveis independentes, 1.218 pessoas seriam necessárias, incluídos $10,0 \%$ para perdas e $15,0 \%$ para controle de fatores de confusão. Para os cálculos de precisão foram utilizados nível de confiança de $95 \%$ e poder de $80,0 \%$ para detectar riscos relativos iguais ou maiores do que 2,0. A amostra total incluiu 1.705 indivíduos, devido ao fato de este estudo fazer parte de uma pesquisa maior, relacionada à saúde da população, incluindo outros desfechos que requereram amostras maiores.

A coleta dos dados foi realizada no período de setembro a dezembro de 2003, para a qual foram contratadas e treinadas entrevistadoras com idade igual ou superior a 18 anos e ensino médio de escolaridade. O instrumento de pesquisa utilizado foi um questionário individual pré-testado, composto de uma parte específica relativa ao estudo e outra que incluiu variáveis demográficas e sócio-econômicas. Indivíduos que se recusaram a participar da pesquisa ou que não se encontravam no domicílio no momento da primeira visita, foram procurados, pelo menos, mais três vezes. A última tentativa foi realizada pelo supervisor do trabalho de campo.

Com a intenção de verificar a veracidade da entrevista e a correta aplicação do instrumento de pesquisa, foi realizado o controle de qualidade pelos supervisores do trabalho de campo, sendo utilizado um questionário reduzido aplicado a $10,0 \%$ da amostra, selecionada aleatoriamente. Para comparação dos resultados ob- 
tidos nesses questionários utilizou-se o índice kappa.

A análise descritiva foi realizada com o objetivo de apresentar a amostra em relação às variáveis demográficas e sócio-econômicas, padrões de utilização e equipamentos de segurança da bicicleta, bem como aos acidentes ocorridos no último ano. Associações entre a utilização da bicicleta e variáveis demográficas e sócio-econômicas foram investigadas por meio de razões de prevalência. A análise ajustada baseou-se no modelo conceitual proposto, no qual variáveis demográficas e sócio-econômicas apresentaram-se no mesmo nível. Em ambas as análises (bruta e ajustada) foi utilizada a regressão de Poisson devido a mesma estimar diretamente as razões de prevalência, facilitando a interpretação dos resultados 16. Igualmente, foi considerado o efeito de delineamento do estudo por meio do conjunto de comandos svy, específico para a análise de inquéritos baseados em amostras complexas. As análises foram realizadas utilizando-se o Programa Estatístico Stata 8.0. A entrada dos dados, duplamente digitados e com checagem automática de consistência e amplitude, bem como o cálculo do tamanho da amostra, foram feitos com o auxílio do programa Epi Info 6.0.

Este estudo foi aprovado pela Comissão de Ética e Pesquisa da Universidade Federal de Pelotas. Seus objetivos e o compromisso de confidencialidade das informações foram explicitados e a entrevista foi realizada somente após o consentimento verbal do entrevistado.

\section{Resultados}

Nos 1.530 domicílios visitados foram encontradas 3.709 pessoas com 15 anos ou mais de idade. Dessas, 3.542 foram entrevistadas, tendo ocorrido $3,4 \%$ de perdas e recusas. Dos entrevistados, $48,1 \%$ (1.705) trabalhavam fora do domicílio e constituíram a população em estudo. $O$ efeito de delineamento foi de 2,6 e o índice kappa, relacionado ao controle de qualidade do estudo para questão relacionada à utilização de modos de transporte, foi de 0,88 .

A Tabela 1 descreve a amostra estudada, na qual observa-se que mais da metade era do sexo masculino, cerca de $70,0 \%$ apresentavam idades entre 25 e 54 anos e aproximadamente $80,0 \%$ tinham a cor da pele branca. Cerca de um terço encontrava-se no nível econômico intermediário e quase metade da amostra possuía nove anos ou mais de escolaridade.

A prevalência de utilização da bicicleta na população de trabalhadores estudada foi de
17,2\% (IC95\%: 15,4-19,0). O modo de transporte mais utilizado foi o ônibus $(32,1 \%)$, seguido dos modos a pé $(21,7 \%)$, automóvel $(21,4 \%)$, bicicleta, motocicleta $(6,0 \%)$ e outros modos $(1,6 \%)$. Entre os homens a bicicleta foi o modo de transporte mais utilizado $(27,1 \%)$, seguido do automóvel $(24,2 \%)$ e do ônibus $(19,9 \%)$, enquanto que a maioria das mulheres utilizou o ônibus $(48,8 \%)$ e o modo a pé $(27,5 \%)$.

Como mostra a Tabela 2, enquanto $27,1 \%$ dos homens relataram utilizar a bicicleta como modo de transporte nas viagens para o trabalho, entre as mulheres essa proporção foi de $4,1 \%$. Esses resultados foram semelhantes quando ajustados para as demais variáveis. Não houve diferença nas prevalências de uso da bicicleta em relação à idade.

A variável cor da pele, que na análise bruta mostrou-se significativamente associada à utilização da bicicleta, quando ajustada para fatores sócio-econômicos não se manteve estatisticamente significativa.

Ainda na Tabela 2, observa-se que o nível econômico foi inversamente proporcional à utilização da bicicleta, tanto na análise bruta como na ajustada. Esses resultados mostraram que os trabalhadores do menor quintil econômico apresentaram cerca de 15 vezes mais chances para o uso desse modo de transporte, quando comparados aos de níveis mais elevados (5o quintil).

Igualmente ao nível econômico, a escolaridade mostrou associação linear, inversamente proporcional, com o desfecho. Este estudo demonstrou, além da alta prevalência de utilização entre trabalhadores com baixa escolaridade $(33,9 \%)$, uma probabilidade aproximadamente cinco vezes maior de esses utilizarem a bicicleta, em comparação a trabalhadores com escolaridade igual ou superior a nove anos de estudo.

Em relação aos padrões de utilização (Tabela 3), 87,0\% dos trabalhadores que utilizavam a bicicleta o faziam por, pelo menos, cinco dias na semana. A variável tempo de utilização diária, apresentou mediana de 40 minutos/dia e média de 57 minutos/dia. Mais de dois terços utilizavam a bicicleta nas viagens para o trabalho por um período superior a 30 minutos/dia.

As prevalências de utilização, relacionadas às condições climáticas, demonstraram que a grande maioria dos trabalhadores a utilizava mesmo em condições desfavoráveis. Setenta e um por cento a utilizavam em dias de chuva, $99,0 \%$ em dias de muito calor e $95,0 \%$ em dias muito frios. Quase $80,0 \%$ dos entrevistados utilizavam a bicicleta durante a noite, em viagens para o trabalho. 
Em relação aos equipamentos de segurança exigidos pelo Código de Trânsito Brasileiro (CTB) 17 , apenas $0,3 \%$ das bicicletas observadas os apresentava em sua totalidade, enquanto $14,0 \%$ não apresentavam quaisquer desses equipamentos. A maioria delas $(55,0 \%)$ possuía apenas um dos equipamentos exigidos. Em $15,0 \%$ das bicicletas não havia freios funcionando e o refletor instalado nos pedais foi o equipamento de segurança obrigatório mais utilizado. As prevalências de utilização desses equipamentos são mostradas na Figura 1.

A prevalência de acidentes, no último ano, com trabalhadores que utilizavam a bicicleta como modo de transporte para o trabalho foi de 5,5\% (IC95\%: 2,8-8,1). Como mostra a Tabela 4, 15 ciclistas $(94,0 \%)$ acidentaram-se uma vez no período estudado. Quanto à gravidade do acidente, 12 ciclistas $(75,0 \%)$ tiveram arranhões e escoriações, enquanto $4(25,0 \%)$ apresentaram lesões mais graves. Devido aos ferimentos sofridos, 3 desses trabalhadores (19,0\%) faltaram ao trabalho por, pelo menos, um dia.

Dados não apresentados nas tabelas indicam que 14 ciclistas (cerca de $90,0 \%$ ) que se acidentaram utilizavam a bicicleta por, pelo menos, cinco dias na semana e 11 (mais de dois terços) a utilizavam por mais de 30 minutos por dia. Dos acidentados, 13 (81,0\%) relataram utilizar a bicicleta à noite.

Das 16 bicicletas utilizadas por trabalhadores que se acidentaram, 12 (75,0\%) possuíam apenas um equipamento de segurança exigido pelo CTB, enquanto 4 (25,0\%) não possuíam quaisquer desses equipamentos.

\section{Discussão}

A prevalência de utilização da bicicleta em Pelotas pode ser comparada a prevalências de cidades européias 2. Entretanto, a utilização exclusiva como modo de transporte para o trabalho é muito rara na maioria dessas cidades. No Brasil, a inexistência de estudos de base-populacional relacionados a esse tema, dificulta a comparação com cidades brasileiras. Considerando a metodologia utilizada e o percentual de perdas e recusas, este estudo é representativo da população trabalhadora com 15 anos ou mais de idade, residente na zona urbana dessa cidade. Extrapolando os resultados da prevalência de utilização da bicicleta encontrada para essa população, este estudo pode afirmar que existem na cidade de Pelotas, aproximadamente, 18 mil trabalhadores que utilizam esse modo de transporte em seus deslocamentos diários para o trabalho.
Tabela 1

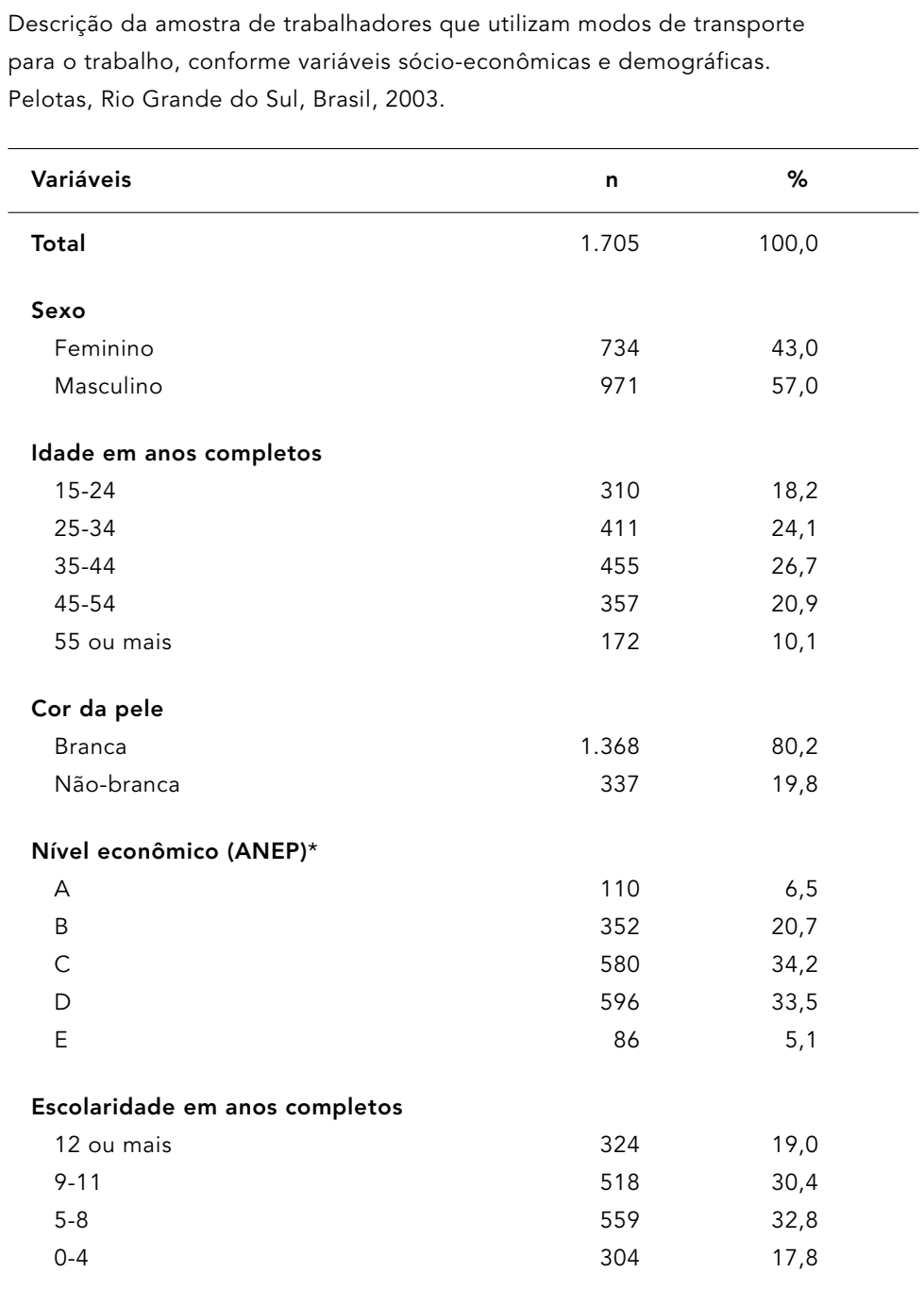

*Valores ignorados $=8$.

Em relação ao sexo, a diferença de utilização entre homens e mulheres apontada nesta pesquisa coincide com outros estudos que indicam um maior uso da bicicleta por parte dos homens 18 , principalmente quando a utilização é referida para deslocamentos ao trabalho 19 . Na China, onde a bicicleta é largamente utilizada como modo de transporte, essa diferença não é observada 20.

Com relação à faixa etária, este estudo mostrou que trabalhadores de todas as idades utilizam a bicicleta, assim como os ciclistas europeus 21, principalmente da Holanda e Dinamarca 4 e ciclistas chineses 20 , diferentemente dos ciclistas norte-americanos, onde adultos jovens são os principais usuários 19,21.

Este estudo não encontrou associação significativa entre cor da pele e utilização da bici- 
Prevalência, análise bruta e ajustada por regressão de Poisson da utilização da bicicleta entre os trabalhadores, em relação a variáveis demográficas e sócio-econômicas. Pelotas, Rio de Grande do Sul, Brasil, 2003.

\begin{tabular}{|c|c|c|c|c|c|}
\hline \multirow[t]{2}{*}{ Variáveis } & \multirow[t]{2}{*}{ Prevalência (\%) } & \multicolumn{2}{|c|}{ Análise bruta } & \multicolumn{2}{|c|}{ Análise ajustada* } \\
\hline & & $\mathrm{RP}(\mathrm{IC} 95 \%)^{\star \star}$ & Valor $p$ & $\mathrm{RP}(\mathrm{IC} 95 \%)^{\star \star *}$ & Valor $\mathrm{p}$ \\
\hline Sexo & & & $<0,001^{\star \star \star}$ & & $<0,001^{\star * *}$ \\
\hline Feminino & 4,1 & 1,0 & & 1,0 & \\
\hline Masculino & 27,1 & $6,6(4,7-9,3)$ & & $5,6(3,9-7,9)$ & \\
\hline Idade (anos) & & & $0,8 \#$ & & $0,4 \#$ \\
\hline $15-24$ & 16,8 & 1,0 & & 1,0 & \\
\hline $25-34$ & 19,7 & $1,2(0,9-1,6)$ & & $1,2(0,9-1,6)$ & \\
\hline $35-44$ & 14,5 & $0,9(0,6-1,2)$ & & $0,9(0,7-1,3)$ & \\
\hline $45-54$ & 17,9 & $1,1(0,8-1,5)$ & & $1,2(0,9-1,6)$ & \\
\hline 55 ou mais & 17,4 & $1,0(0,7-1,5)$ & & $0,8(0,6-1,2)$ & \\
\hline Cor da pele & & & $0,005^{\star \star *}$ & & $0,18^{\star \star \star}$ \\
\hline Branca & 15,9 & 1,0 & & 1,0 & \\
\hline Não-branca & 22,6 & $1,4(1,1-1,8)$ & & $0,9(0,7-1,1)$ & \\
\hline Nível econômico (ANEP) & & & $<0,001 \#$ & & $<0,001 \#$ \\
\hline 5의 quintil & 2,1 & 1,0 & & 1,0 & \\
\hline 4o quintil & 4,9 & $2,3(0,9-6,4)$ & & $2,4(0,9-6,4)$ & \\
\hline 3o quintil & 15,8 & $7,6(3,0-18,8)$ & & $6,9(2,8-16,9)$ & \\
\hline 2o quintil & 22,6 & $10,9(4,6-25,6)$ & & $10,9(4,6-25,5)$ & \\
\hline 1ㅇq quintil & 35,4 & $17,0(7,2-39,9)$ & & $15,8(6,8-36,6)$ & \\
\hline Escolaridade (anos) & & & $<0,001 \#$ & & $0,001 \#$ \\
\hline 9 ou mais & 6,1 & 1,0 & & 1,0 & \\
\hline $5-8$ & 24,9 & $4,1(2,9-5,9)$ & & $3,5(2,4-5,0)$ & \\
\hline $0-4$ & 33,9 & $5,6(3,9-8,0)$ & & $4,8(3,7-6,7)$ & \\
\hline
\end{tabular}

* Todas as variáveis estão controladas para as demais, com exceção do nível econômico que não foi controlada para escolaridade e vice-versa.

$\star \star \mathrm{RP}=$ razão de prevalência; IC $95 \%$ = intervalo de confiança de $95 \%$.

$\star \star \star$ Teste de heterogeneidade de proporções.

\# Teste de tendência linear.

cleta como modo de transporte para o trabalho. Resultado similar foi observado em estudo norte-americano onde as prevalências de utilização foram semelhantes entre minorias étnicas 22 .

Sexo, nível econômico e escolaridade, devido à força de associação e o efeito dose-resposta, podem ser considerados os principais determinantes da utilização da bicicleta entre os trabalhadores de Pelotas. Várias pesquisas indicam a renda como fator preponderante para a escolha da bicicleta, em se tratando de deslocamentos para o trabalho 4,19,23,24,25. Trabalhadores de níveis sociais mais baixos vêem na bicicleta uma forma de economia frente aos custos de aquisição e manutenção de um automóvel ou mesmo em relação ao transporte coletivo.

Quanto aos padrões de utilização, resultados relacionados aos dias na semana de utili- zação da bicicleta coincidem com outros estudos. Em Araçatuba, São Paulo, Brasil, 86,0\% dos ciclistas que utilizam a bicicleta para ir ao trabalho o fazem por, pelo menos, cinco dias na semana 25 , enquanto que a maioria dos ciclistas de Shangai usa a bicicleta por, ao menos, seis dias 20 . A média de 57 minutos de deslocamento diário para ir e voltar do trabalho, encontrada no presente estudo, foi superior às médias entre 20 e 30 minutos encontradas nas cidades chinesas de Taijin 26 e Boading 27.

Um ponto importante a ser considerado é o benefício para a saúde que esses trabalhadores têm em virtude do seu grau elevado de atividade física decorrente do uso regular da bicicleta. Estudos mostram que indivíduos que praticam, pelo menos, trinta minutos diários de atividade física moderada (na qual se inclui o ci- 
clismo) por, pelo menos, cinco dias na semana, têm menor risco de doença coronariana, hipertensão arterial, diabetes tipo 2, alguns tipos de câncer, depressão, osteoporose, entre outras doenças 28,29. Dos 293 ciclistas incluídos neste estudo, 74,0\% atingiram tal recomendação, tendo, portanto, benefícios significativos para a saúde.

As altas prevalências de utilização da bicicleta para ir ao trabalho em dias de muito frio, muito calor ou dias de chuva obtidas neste estudo, reforçam as conclusões de pesquisas realizadas na Suécia 30 e no Brasil 25 que afirmam que viagens utilitárias são realizadas mesmo em condições meteorológicas desfavoráveis. Entretanto, a diminuição do uso em dias de chuva está de acordo com um estudo feito na Austrália 31 que afirma ser esse fator meteorológico o mais importante na decisão de utilizar esse modo de transporte.

Segundo Rodgers 8, o uso da bicicleta após anoitecer está associado com maiores riscos de acidentes fatais. Williams \& Boyd 32 afirmam que a utilização de refletores e faroletes na bicicleta, com a intenção de fazer o ciclista mais visível à noite, pode prevenir muitos acidentes. Grande parte dos trabalhadores entrevistados neste estudo utilizava a bicicleta no período noturno devido ao fato de que, em determinados meses do ano a ida para o trabalho ocorre antes do amanhecer e o retorno para casa após o anoitecer. Essa acentuada utilização à noite, somada à baixa prevalência de uso de refletores e faroletes, são fatores que podem ter influenciado na grande ocorrência de acidentes observada nesta pesquisa.

Apesar de não ter sido encontrado nenhum estudo no Brasil que faça referência à utilização de equipamentos de segurança da bicicleta, os dados aqui apresentados merecem atenção especial, pois identificam problemas e podem apontar algumas medidas para diminuir o elevado número de acidentes envolvendo ciclistas. A baixa prevalência encontrada no uso dos equipamentos obrigatórios pelo Código de Trânsito Brasileiro corroboram com o mencionado no relatório do GEIPOT 5, que faz referência ao baixo nível de conhecimento da população de Pelotas quanto às normas desse código. Outro ponto a ser discutido em relação ao baixo uso de equipamentos de segurança é o fato da grande maioria dos ciclistas de Pelotas pertencer a classes menos favorecidas e, conseqüentemente, com menos acesso a informações relativas à segurança no trânsito, além de não possuir renda suficiente para equipar ou mesmo manter sua bicicleta em boas condições. Esses aspectos talvez possam explicar a falta de freios em 15,0\% das bicicletas exami-
Tabela 3

\begin{tabular}{|c|c|c|}
\hline Variáveis & $n^{*}$ & $\%$ \\
\hline Total & 293 & 100,0 \\
\hline \multicolumn{3}{|c|}{ Dias na semana } \\
\hline Até 4 & 38 & 13,0 \\
\hline 5 & 103 & 31,5 \\
\hline 6 & 113 & 38,6 \\
\hline 7 & 39 & 13,3 \\
\hline \multicolumn{3}{|c|}{ Tempo de utilização p/dia (minutos) } \\
\hline Até 30 & 85 & 29,0 \\
\hline De 31-60 & 141 & 48,1 \\
\hline Mais de 60 & 67 & 22,9 \\
\hline \multicolumn{3}{|c|}{ Utilização em dias de chuva } \\
\hline Sim & 208 & 71,0 \\
\hline Não & 85 & 29,0 \\
\hline \multicolumn{3}{|c|}{ Utilização em dias de muito calor } \\
\hline Sim & 290 & 99,0 \\
\hline Não & 3 & 1,0 \\
\hline \multicolumn{3}{|c|}{ Utilização em dias de muito frio } \\
\hline Sim & 277 & 94,5 \\
\hline Não & 16 & 5,5 \\
\hline \multicolumn{3}{|c|}{ Utilização à noite } \\
\hline Sim & 225 & 76,8 \\
\hline Não & 68 & 23,2 \\
\hline
\end{tabular}

* Número de trabalhadores que utiliza a bicicleta.

nadas, que não é considerado equipamento de segurança obrigatório pelo CTB.

Em relação à descrição dos acidentes, este estudo identificou ciclistas que se acidentaram nos últimos 12 meses e continuaram a utilizar a bicicleta como principal modo de transporte. Ciclistas que sofreram algum acidente grave e ficaram incapacitados de utilizá-la não foram captados pelo estudo, bem como, obviamente, os que faleceram em decorrência do acidente. Entretanto, esse resultado não deve ser visto como um viés devido à baixa probabilidade de ocorrência dos casos descritos anteriormente na fração amostral estudada. O período recordatório de até 12 meses utilizado neste estudo, talvez possa ter levado a um viés de informação (memória) subestimando o número de acidentes leves ocorridos próximo ao limiar desse período. 
Prevalência de equipamentos de segurança das bicicletas de trabalhadores que a utilizam como modo de transporte. Pelotas, Rio Grande do Sul, Brasil, 2003.

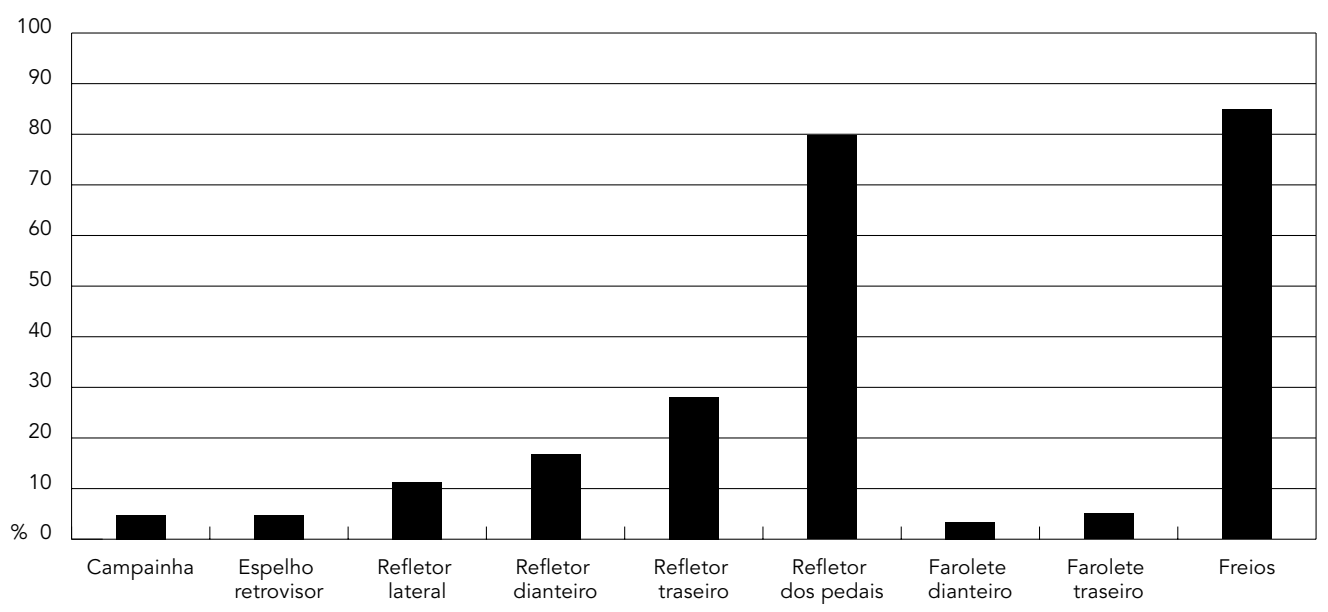

Tabela 4

Descrição dos acidentes sofridos nos últimos doze meses pelos trabalhadores que utilizam a bicicleta como modo de transporte quanto à freqüência, gravidade e faltas ao trabalho. Pelotas, Rio Grande do Sul, Brasil, 2003.

\begin{tabular}{|c|c|c|}
\hline Variáveis & $n^{\star}$ & $\%$ \\
\hline \multicolumn{3}{|c|}{ Acidentou-se no último ano $(n=293)$} \\
\hline $\operatorname{Sim}$ & 16 & 5,5 \\
\hline Não & 277 & 94,5 \\
\hline \multicolumn{3}{|c|}{$\begin{array}{l}\text { Número de acidentes no último ano } \\
(n=16)\end{array}$} \\
\hline 1 acidente & 15 & 93,8 \\
\hline Mais de 1 acidente & 1 & 6,2 \\
\hline \multicolumn{3}{|l|}{ Gravidade do acidente $(n=16)$} \\
\hline Arranhão ou escoriação & 12 & 75,1 \\
\hline Batida forte & 2 & 12,5 \\
\hline Corte ou perfuração na pele & 1 & 6,2 \\
\hline Fratura & 1 & 6,2 \\
\hline \multicolumn{3}{|l|}{$\begin{array}{l}\text { Dias de falta ao trabalho devido } \\
\text { ao acidente }(n=16)\end{array}$} \\
\hline Nenhum dia & 13 & 81,4 \\
\hline $1 \mathrm{dia}$ & 1 & 6,2 \\
\hline 7 ou mais dias & 2 & 12,4 \\
\hline
\end{tabular}

* Número de trabalhadores que utiliza a bicicleta.
A prevalência de 5,5\% de ciclistas acidentados nos últimos 12 meses demonstra o risco a que está exposto o trabalhador que utiliza a bicicleta nos deslocamentos para o trabalho. Novamente extrapolando os dados para a população trabalhadora com 15 anos ou mais de idade, este estudo aponta a ocorrência de, aproximadamente, mil acidentes com lesão corporal no espaço de tempo de 12 meses. Esses valores são muito superiores aos dados estatísticos de acidentes envolvendo ciclistas de Pelotas. Cabe lembrar que o número de acidentes mencionado acima é relativo apenas aos deslocamentos de ida e vinda do trabalho para casa.

Em relação a esses acidentes, observou-se que a maioria dos ciclistas sofreu ferimentos leves (arranhões e escoriações) e não necessitou faltar ao trabalho em decorrência dos ferimentos. Os acidentes mais graves (fratura e batida forte) obrigaram os trabalhadores ao absenteísmo. Cabe ressaltar se o não faltar ao trabalho foi decorrente da pequena gravidade do ferimento ou se esses trabalhadores compareceram ao trabalho mesmo com o desconforto causado pelo trauma sofrido. Muitos deles pertencem a classes menos privilegiadas, trabalhando por conta própria ou no trabalho informal, sem direito a garantias trabalhistas. A falta ao trabalho comprometeria a renda familiar e geraria sérios problemas sociais.

Em conclusão, considerando o grande número de trabalhadores de Pelotas que utilizam 
a bicicleta como modo de transporte e as características sócio-econômicas dessa população; considerando ainda a elevada ocorrência de acidentes de transporte terrestre e a baixa prevalência de utilização de equipamentos de segurança nas bicicletas desses trabalhadores, este estudo sugere a necessidade de intervenções que garantam a segurança deles no deslocamento para o trabalho. Fazem-se também necessários estudos relacionados ao comportamento no trânsito, de ciclistas e de outros

\section{Resumo}

Um estudo transversal de base-populacional foi realizado em Pelotas, sul do Brasil, objetivando pesquisar os determinantes e padrões de utilização da bicicleta como modo de transporte para o trabalho. Foram também descritos os acidentes ocorridos nos últimos 12 meses no deslocamento de ida e volta para o trabalho e a utilização de equipamentos de segurança na bicicleta. A amostra incluiu 1.705 trabalhadores com 15 anos ou mais de idade, residentes na zona urbana, que utilizavam modos de transporte para o trabalho. Análises bruta e ajustada foram realizadas por meio de regressão de Poisson, considerando o efeito do delineamento. A prevalência de utilização da bicicleta foi de 17,2\% (IC95\%: 15,4-19,0). Trabalhadores homens, com baixa escolaridade e nível econômico mais baixo apresentaram as maiores prevalências. Menos de 1,0\% das bicicletas possuía os equipamentos de segurança exigidos pelo Código de Trânsito Brasileiro e 15,0\% não tinham freios. Aproximadamente 6,0\% desses trabalhadores sofreram acidentes de trânsito com lesões corporais nos últimos 12 meses. Concluímos que trabalhadores que utilizam bicicleta como modo de transporte são prioritários para intervenções preventivas relacionadas a acidentes de trânsito.

Acidentes de Trânsito; Trabalhadores; Ciclismo usuários de vias públicas. A construção de espaços exclusivos à circulação de bicicletas, a disseminação de conhecimento relativo aos direitos e deveres desses cidadãos frente às leis de trânsito e uma maior fiscalização para garantir o cumprimento do CTB seriam medidas que, em curto e médio prazo, com certeza, reduziriam o número de acidentes envolvendo ciclistas e, conseqüentemente, o número de acidentes de transporte terrestre.

\section{Colaboradores}

G. Bacchieri participou de todas as fases de produção do artigo, desde o planejamento até a coleta e análise dos dados e redação. D. P. Gigante contribuiu no planejamento, na análise dos dados, na interpretação dos achados e na revisão crítica do manuscrito. M. C. Assunção participou do planejamento, auxiliou na fase de análise dos dados e na revisão crítica do artigo. 


\section{Referências}

1. Federal Highway Administration. Measures to overcome impediments to bicycling and walking: case study n. 4. Washington DC: Federal Highway Administration, US Department Transportation; 1993.

2. International Bicycle Fund. Bicycle statistics usage, production, sales, import, export. http://www. ibike.org/statistics.htm (acessado em 25/Jun/ 2003).

3. Associação Nacional de Transportes Públicos. Chineses reduzem o uso da bicicleta nas cidades. Informativo ANTP 2001; mai:82.

4. Pucher J, Komanof C, Schimek P. Bicycling renaissance in North America? Recent trends and alternative policies to promote bicycling. Transportation Research Part A 1999; 33:625-54.

5. Empresa Brasileira de Planejamento de Transportes. Planejamento cicloviário: diagnóstico nacional. Brasília: Empresa Brasileira de Planejamento de Transportes; 2001.

6. Andersen LB, Schnohr P, Schroll M, Hein HO. Allcause mortality associated with physical activity during leisure time, work, sports, and cycling to work. Archives of Internal Medicine 2000; 160: 1621-8.

7. Li GH, Baker SP. Injuries to bicyclists in Wuhan, People's Republic of China. Am J Public Health 1997; 87:1049-52.

8. Rodgers GB. Bicyclist deaths and fatality risk patterns. Accident Analysis and Prevention 1995; 27:215-23.

9. Dennerlein JT, Meeker JD. Occupational injuries among Boston bicycle messengers. American Journal of Industrial Medicine 2002; 42:519-25.

10. Gonçalves RM, Petroianu A, Junior JR. Características das pessoas envolvidas em acidentes com veículos de duas rodas. Rev Saúde Pública 1997; 31:436-7.

11. Barros AJ, Amaral RL, Oliveira MS, Lima SC, Gonçalves EV. Acidentes de trânsito com vítimas: sub-registro, caracterização e letalidade. Cad Saúde Pública 2003; 19:979-86.

12. Andrade SM, Mello-Jorge MHP. Acidentes de transporte terrestre em cidade da região sul do Brasil: avaliação da cobertura e qualidade dos dados. Cad Saúde Pública 2001; 17:1449-56.

13. Secretaria Municipal de Transportes e Trânsito. Relatório de totais de ocorrências. Pelotas: Secretaria Municipal de Transportes e Trânsito; 2004.

14. Scalassara MB, De Souza RK, Soares D. Características da mortalidade por acidentes de trânsito em localidade da Região Sul do Brasil. Rev Saúde Pública 1998; 32:125-32.

15. Associação Nacional de Empresas de Pesquisa. Critérios de classificação econômica do Brasil. São Paulo: Associação Nacional de Empresas de Pesquisa; 2002.

16. Hirakata VN. Alternativas de análise para um desfecho binário em estudos transversais e longitudinais [Dissertação de Mestrado]. Pelotas: Universidade Federal de Pelotas; 1999.
17. Sobrinho JA, Barbosa MM, Mukai NSN. Código de trânsito brasileiro anotado e legislação complementar em vigor. São Paulo: Editora Método; 2002.

18. Osberg JS, Stiles SC, Asare OK. Bicycle safety behavior in Paris and Boston. Accid Anal Prev 1998; 30:679-87.

19. Federal Highway Administration. Reasons why bicycling and walking are and are not being used more extensively as travel modes: case study no 1 . Washington DC: Federal Highway Administration, US Department Transportation; 1992.

20. Tanaboriboon Y, Ying G. Characteistics of bicycle users in Shangai, China. Transportation Research Record 1993; 1396:22-9.

21. Pucher J, Dijkstra L. Making walker and cycling safer: lessons from Europe. Transportation Quarterly 2000; 54:25-50.

22. Baltes MR. Factors influencing nondiscretionary work trips by bicycle determined from 1990 US Census Metropolitan Statistical Area Data. Transportation Research Record 1996; 1538:96-101.

23. Dill J, Carr T. Bicycle commuting and facilities in major U.S. cities: if you build them, commuters will use them - another look. In: Transportation Research Board - Annual Meeting [CD-ROM]. Portland: Portland State University; 2003.

24. Ortúzar JD, Iacobelli A, Valeze C. Estimating demand for cycleway networks. Transportation Research Parte A: Policy and Practice 1999; 34:35373.

25. Pezzuto CC. Fatores que influenciam o uso da bicicleta [Dissertação de Mestrado]. São Carlos: Universidade Federal de São Carlos; 2002.

26. Hu G, Pekkarinen H, Hanninen O, Yu ZJ, Tian HG, Guo ZY, Nissinen A. Physical activity during leisure and commuting in Tianjin, China. Bull World Health Org 2002; 80:933-8.

27. Kubota H, Kidokoro T. Analysis of bicycle-dependent transport systems in China: case study in a medium-size city. Transportation Research Record 1994; 1441:11-5.

28. Pate RR, Pratt M, Blair SN, Haskell WL, Macera CA, Bouchard C, et al. Physical activity and public health. A recommendation from the Centers for Disease Control and Prevention and the American College of Sports Medicine. JAMA 1995; 273: 402-7.

29. Bauman AE. Updating the evidence that physical activity is good for health: an epidemiological review 2000-2003. J Sci Med Sport 2004; 7:6-19.

30. Hanson S, Hanson P. Evaluating the impact of weather on bicycle use. Transportation Research Record 1977; 629:43-8.

31. Nankervis M. The effect of weather and climate on bicycle commuting. Transportation Research Part A: Policy and Practice 1999; 33:417-31.

32. Williams J, Boyd H. Howard boyd on: in training England's Cyclist (interview of Howard Boyd). Bicycle Forum 1982; 8:24-31.

Recebido em 23/Nov/2004

Aprovado em 18/Abr/2005 